Jurnal KIBASP (Kajian Bahasa, Sastra dan Pengajaran)

Volume 2, Nomor 1, Desember 2018

e-ISSN : 2597-5218

p-ISSN : 2597-520X

DOI: https://doi.org/10.31539/kibasp.v2i1.458

\title{
PEMERTAHANAN BAHASA SINDANG PADA MASYARAKAT KOTA LUBUKLINGGAU
}

\author{
Nur Nisai Muslihah ${ }^{1}$, Rusmana Dewi ${ }^{2}$, Lessy Puspitasari ${ }^{3}$ \\ Program Studi Pendidikan Bahasa dan Sastra Indonesia \\ STKIP-PGRI Lubuklinggau ${ }^{1,2,3}$ \\ nurnisai@yahoo.co.id ${ }^{1}$
}

Submit, 29-11-2018 Accepted,29-12-2018 Publish, 29-12-2018

\begin{abstract}
ABSTRAK
Penelitian ini bertujuan untuk mendeskripsikan pemertahanan bahasa Sindang di Kelurahan Watervang Kota Lubuklinggau yang difokuskan pada pemertahanan bahasa Sindang pada ranah remaja dan dewasa. Penelitian ini termasuk jenis penelitian deskriptif kuantitatif dengan subjek penelitiannya adalah remaja dan dewasa yang berjumlah 59 orang. Pengumpulan data dilakukan dengan menggunakan teknik angket tertutup. Selanjutnya analisis data dengan menggunakan rumus persentase. Hasil analisis data diketahui bahwa sikap pemertahanan bahasa Sindang pada masyarakat dari golongan remaja diperoleh rata-rata sebesar 73,01 dengan kategori baik, dan untuk golongan dewasa diperoleh rata-rata sebesar 80,57 dengan kategori baik. Berdasarkan perhitungan rata-rata dari kedua golongan subjek yang diteliti dapat disimpulkan bahwa sikap pemertahanan bahasa Sindang pada masyarakat di Kelurahan Watervang Kecamatan Lubuklinggau Timur 1 Kota Lubuklinggau dengan kategori baik.
\end{abstract}

Kata Kunci: Pemertahanan, Bahasa Sindang, Kelurahan Watervang.

\begin{abstract}
This research aims at describing the maintenance of Sindang language in Watervang subdistrict Lubuklinggau city which was focused on the maintenance of Sindang language in teenagers and adults domain. The research was a quantitative descriptive research with 59 informants of teenagers and adults. The data collection was conducted through closed questionnaire. The data were analyzed by using percentage calculation. The results showed that the maintenance of Sindang language on teenagers group was 73,01 with 'good'category, and on adults group was 80,57 with 'good' category. Based on the average calculation, it can be concluded that the attitude of the language maintenance on Sindang language among teenagers and adults in Watervang subdistrict Lubuklinggau city is in 'good'criteria.
\end{abstract}

Keywords: Maintenance, Sindang Language, Watervang Subdistrict 


\section{PENDAHULUAN}

Pemertahanan bahasa merupakan suatu upaya yang dilakukan oleh seseorang maupun kelompok masyarakat untuk mempertahankan keberadaan bahasa daerahnya maupun bangsanya agar tetap digunakan dalam kehidupan sehari-hari. Usaha ini berupa upaya seseorang untuk tetap menggunakan bahasanya sebagai identitas seseorang baik dalam masyarakat maupun di luar masyarakat. Semua ini dilakukan agar bahasa daerahnya atau bangsanya tetap bertahan dan tidak mengalami kepunahan. Hal ini selaras dengan pernyataan Crystal (Suandi, 2014) bahwa pemertahanan bahasa (Language Maintenance) adalah upaya yang disengaja untuk mempertahankan suatu bahasa tertentu di suatu wilayah yang memiliki keberagaman bahasa dan budaya sebagai wujud diversitas cultural dalam rangka memelihara identitas etnis dan adaptabilitas sosial. Dengan kata lain, pemertahanan bahasa erat kaitannya dengan ranah yang berkaitan dengan pilihan bahasa (Rokhman, dalam Rianto, 2016).

Pemertahanan bahasa sangat diperlukan oleh bangsa atau daerah untuk menunjukkan keberadaan dirinya. Apakah masih dikatakan bertahan atau telah punah. Konsep tentang pemertahanan bahasa adalah konsep yang terkait erat dengan perencanaan bahasa (Kaplan dalam Istianingrum, 2015). Keberadaan suatu bahasa tidak terlepas dari sikap para penutur bahasa yang bersangkutan. untuk menggunakannya dalam kehidupan sehari-hari (Maemunah. 2017). Jumlah penutur yang besar tidak telalu penting bagi pemertahanan bahasa. Kelompok yang kecil pun dapat mempertahankan bahasanya jika mereka memiliki sikap yang positif terhadap bahasanya.

Pemertahanan bahasa juga mencakup perubahan bahasa (language change), peralihan bahasa (language shift), dan kematian bahasa (language death). Terkait dengan hal ini Fauzi (Suandi, 2014) dan Fauzi (Nugroho, 2017) mengemukakan bahwa jika suatu komunitas bahasa tidak mampu mempertahankan bahasanya, secara bertahap memungut kosakata bahasa yang lain, maka akan mengarah pada pergeseran bahasa (language shift). Sedangkan untuk pemertahanan bahasa (language maintenance) lebih mengarah kepada situasi di mana suatu komunitas bahasa yang berusaha menggunakan bahasanya untuk menjaga bahasa yang dimilikinya yaitu bahasa daerah atau bahasa ibunya. Menurut Sedyawati (Sahril, 2016) fungsi bahasa ibu atau bahasa daerah adalah sebagai alternatif sarana yang paling ekspresif untuk berkomunikasi sesuai dengan suasana naluriah dan batiniah penuturnya. 
Pemertahanan bahasa merupakan sikap dan upaya seseorang untuk mempertahankan serta melestarikan bahasanya dengan tetap menggunakan bahasanya ketika berinteraksi dengan bahasa-bahasa lainnya. Sikap merupakan suatu perilaku seseorang yang mempunyai norma-norma dalam bermasyarakat. Menurut Chaer, (2010), sikap merupakan peristiwa kejiwaan, yang termanifestasi dalam bentuk perbuatan atau tingkah laku. Berkaitan dengan masalah sikap, Aslinda (2007) dan Suandi (2014) mengemukakan bahwa sikap bahasa berkaitan dengan motivasi seseorang yang merujuk pada mental dan perilaku seseorang dalam berbahasa. Sikap bahasa ini dapat diamati melalui perilaku berbahasa atau bertutur. Oleh karena itu, tidak semua perilaku bertutur merupakan sikap bahasa karena sikap bahasa merupakan peristiwa kejiwaan yang tidak dapat diamati secara langsung, tetapi dapat diamati melalui perilaku berbahasa atau perilaku tutur. Yang termasuk dalam sikap bahasa adalah kesopanan mereaksi suatu keadaan dalam berbahasa.

Untuk mengenali sikap bahasa dalam diri seseorang dapat diamati melalui ciriciri perilakunya dalam berbahasa atau bertutur sehingga dapat diketahui sikap bahasanya. Ciri sikap bahasa yang dimaksud diantaranya adalah 1) kesetiaan bahasa (Language loyality). Kesetiaan bahasa akan mendorong seseorang maupun masyarakat suatu bahasa untuk mempertahankan bahasanya, dan mencegah bahasa tersebut mendapat pengaruh dari bahasa lain, 2) kebanggaan bahasa (Language pride). Kebanggaan seseorang terhadap bahasanya akan mendorong seseorang untuk mengembangkan bahasanya dan menggunakannya sebagai lambang identitas dan kesatuan masyarakat, 3) kesadaran adanya norma bahasa (Awareness of the norm). Kesadaran ini mendorong seseorang untuk menggunakan bahasanya dengan cermat dan santun. Hal inilah yang merupakan faktor yang sangat mempengaruhi perbuatan seseorang dalam menggunakan bahasanya (language use) Gavin dan Matiot (Chaer, 2010).

Keberadaan ketiga ciri sikap bahasa tersebut dalam diri seseorang maupun masyarakat menunjukkan bahwa orang atau masyarakat tersebut masih memiliki sikap positif terhadap bahasa. Sebaliknya, dengan menghilang dan melemahnya ciri sikap bahasa tersebut maka orang maupun masyarakat tersebut telah dilanda sikap negatif terhadap bahasanya. 
Berkenaan dengan hal ini, Suandi (2014) mengemukakan bahwa sikap positif bahasa adalah menggunakan bahasa sesuai dengan situasi kebahasaan yang berkaitan dengan: a) penggunaan bahasa sesuai dengan kaidah dan situasi bahasa; b) penggunaan bahasa sendiri tanpa dicampur dengan bahasa asing; dan c) penggunaan bahasa sesuai dengan keperluan. Sedangkan sikap negatif bahasa menyebabkan orang acuh tak acuh terhadap pembinaan pelestarian dan bahasanya. Ia tidak lagi merasa bangga menggunakan bahasanya sendiri sebagai identitas jati diri dan mereka merasa malu menggunakan bahasanya sendiri.

Hal inilah yang menyebabkan orang beralih atau berpindah dari bahasanya sendiri ke bahasa yang lainnya. Kondisi seperti ini terjadi pada masyarakat bilingual maupun multilingual yang menganggap bahwa dengan bahasanya yang baru akan lebih bergengsi dan lebih menjamin seseorang memperoleh kesempatan di sektor modern ataupun semacamnya.Jika penutur suatu bahasa berpindah pada bahasa lain, maka hal ini merupakan suatu indikator bahwa orang tersebut mulai meninggalkan bahasanya sehingga bahasanya akan mengalami kematian bahasa.

Masalah umum yang terjadi dalam suatu masyarakat adalah kelompok atau golongan yang usianya tua lebih bertahan pada bahasanya daripada kelompok yang usianya lebih muda. Hal ini disebabkan karena kelompok yang lebih mudah terpengaruh dan terangsang menggunakan bahasa yang baru yang menunjukkan adanya perubahan yang bersifat kedinamisan. Hal ini menunjukkan bahwa kecenderungan sikap negatif bahasa terjadi pada lapisan kelompok muda. Hal ini sejalan dengan pendapat Wijana (2011) bahwa pemertahanan bahasa oleh suatu masyarakat dipengaruhi oleh beberapa faktor yaitu: 1) kebanggaan berbahasa (linguistic pride); 2) kesadaran akan norma (Iawareness loyality) dan 3) loyalitas bahasa (language loyality).

Masyarakat Indonesia dikenal sebagai masyarakat yang heterogen baik dari segi suku, bahasa dan budayanya. Tingkat heterogenitas inilah yang menyebabkan adanya perbedaan dalam masyarakat sehingga dikenal sebagai masyarakat yang majemuk. Kemajemukan ini menunjukkan adanya keberagaman dari suatu masyarakat sehingga menimbulkan perbedaan. Sebagaimana dikemukakan oleh Nasikun (dalam Handoyo, 2015) bahwa perbedaan suku, bangsa, agama, adat istiadat, dalam suatu daerah secara horizontal disebut juga sebagai ciri masyarakat majemuk. Keberagaman bahasa dan 
penggunaan bahasa pada masyarakat Indonesia merupakan ciri kemajemukan masyarakat Indonesia sebagai masyarakat yang multingual.

Keberagaman masyarakat Indonesia yang kaya akan bahasa ini identik dengan India. Hal ini dikemukakan oleh Grosjean (dalam Muslihah, 2016) bahwa: Indonesia is a country which rich in language and culture, so famous as diversity community. It identikit with India, as said by Grosjean describes the phenomenon where a minority language in a multilingual nation that is influenced by the positive attitude of the speakers, and the attitude that tends tolerant of minority speakers across languages. it also same in Indonesian froe example: if native from particularly mother tongue caused of activity, time, probably will lost their mother tongue as someone's identity.

Kutipan di atas menjelaskan fenomena bangsa yang multilingual dimana keberadaan bahasa minoritas dipengaruhi oleh sikap positif para penuturnya. Selain itu, sikap yang toleran terhadap para penutur antar bahasa minoritas juga sangat mendukung. Hal ini juga terjadi di Indonesia. Penutur yang berbeda bahasa daerahnya, cenderung toleran terhadap penutur bahasa daerah yang lainnya ketika berinteraksi dengan orang yang berlainan bahasa daerahnya sehingga menyebabkan suatu masyarakat menjadi multilingual.

Masyarakat multilingual merupakan salah satu fenomena unik dalam kebahasaan karena dua bahasa atau lebih dikuasai oleh masyarakat yang mendiami daerah tertentu. Bahasa daerah merupakan penamaan bahasa suatu kelompok masyarakat tertentu yang memperlihatkan frekuensi interaksi lebih tinggi di antara mereka dibandingkan dengan mereka yang tidak bertutur dalam bahasa daerah tersebut (Masinambow dan Paul Haenen, 2001). Bahasa daerah di Indonesia jumlahnya sangat banyak. Bahasa daerah merupakan salah satu pembentuk budaya bangsa Indonesia. Demikian juga dengan bahasa Sindang. Bahasa Sindang (Bese Sindang) atau yang lebih dikenal dengan sebutan bahasa $\mathrm{Cul}$ atau bahasa Saling adalah bahasa daerah penduduk marga Sindang yang mendiami daerah sepanjang aliran Sungai Kelingi dan Sungai Beliti di Kota Lubuklinggau dan Musi Rawas (Fatimah, et.all, 1996).

Bahasa Sindang disebut juga dengan bahasa Cul karena dalam percakapan sehari-hari frekuensi pemunculan kata cul yang berarti 'tidak' sangat tinggi. Karena perhatian orang lebih tertumpu pada penggunaan kata itu, maka bahasa daerah ini disebut juga dengan bahasa $\mathrm{Cul}$ (Fatimat, et.all, 1996). Bahasa Sindang ini memiliki 
keunikan tersendiri, keunikan bahasa Sindang ini sebagaimana dikemukakan oleh masyarakat Lubuklinggau dan Musi Rawas dalam hasil penelitian Fatimah, et.all, (1996) bahwa keunikan bahasa Sindang tampak pada kecenderungan intonasi kalimatnya seperti intonasi anak kecil yang baru pandai bicara. Sebagai contoh, jika menera mengucapkan Ku naq kan, maka kalimat itu berarti 'Aku hendak makan'. Maq liq lu yang berasal dari kalimat Maq baliq dulu berarti 'Ibu pulanglah dulu'.

Bahasa Sindang merupakan salah satu bahasa di Indonesia yang masih digunakan sebagai sarana komunikasi masyarakat di kota Lubuklinggau dan sekitarnya. Penutur bahasa Sindang tersebar dalam beberapa daerah di Luar Lubuklinggau yang berbatasan dengan Kabupaten Musi Rawas, Empat Lawang, Lembak, dan Muratara. Masyarakat Lubuklinggau mulai merasa cemas akan eksistensi bahasa Sindang. Pemakaian bahasa Sindang tidak lagi bersifat monolingual, tetapi cenderung multilingual karena masyarakat Lubuklinggau merupakan masyarakat Multilingual dan daerahnya banyak dikunjungi oleh para pendatang dari luar daerah seperti Jawa, Lampung, Padang, Bandung, Bengkulu, Jambi bahkan dari Bima dan Nusa Tenggara.

Penutur bahasa Sindang tersebar dalam beberapa wilayah yang berdekatan dengan Kota Lubuklinggau. Dilihat dari fungsinya, bahasa Sindang adalah sebagai alat komunikasi maupun alat untuk mengenal identitas daerah-daerah di mana bahasa itu digunakan. Bahasa Sindang memiliki fungsi tersendiri sebagai identitas dan jati diri sebagai orang Lubuklinggau agar tidak kehilangan jati dirinya.

Seperti pada masyarakat Kelurahan Watervang Kecamatan Lubuklinggau Timur 1 Kota Lubuklinggau Provinsi Sumatera Selatan, bahasa Sindang merupakan alat komunikasi dalam kehidupan sehari-hari. Penutur bahasa Sindang di daerah ini adalah penduduk asli Lubuklinggau. Namun dalam kenyataannya, penggunaan bahasa Sindang terinterferensi dengan bahasa lain yaitu bahasa Indonesia dan bahasa daerah lainnya seperti bahasa, Palembang, Jawa, Sunda, Batak, Padang, dan sebagainya sehingga memungkinkan terjadinya pergeseran bahasa.

Beberapa penelitian relevan yang telah dilakukan peneliti pendahulu mengenai penertahanan bahasa antara lain: Pertama, penelitian oleh Sahril dengan judul Pemertahanan Bahasa Ibu melalui Grup WA. Penelitian ini difokuskan pada penggunaan bahasa ibu (Bahasa Melayu dialek Batubara) pada komunitas Grup Whatsapp Cendekiawan Batubara. Hasil penelitian menunjukkan bahwa terdapat 
beberapa osakata bahasa Meayu dialek Batubara yang sudah jarang digunakan dalam kehidupan sehari-hari di wilayah Batubara namun muncul dalam dialog grup WA. Kedua, penelitian oleh Hasan Nugroho (2017) dengan judul Pemertahanan Bahasa sebagai Strategi Komunikasi pada Komunikasi Tutorial (Pembelajaran BIPA Kelas Pemula).

Penelitian ini difokuskan pada tutor dan tutorial pembelajar BIPA. Hasil penelitian berupa strategi pembelajaran kegiatan tutorial kelas pemula BIPA kelas pemula, pemertahanan bahasa sebagai sasara menolak komunikasi dengan bahasa Inggris pada saat kegiatan tutorial. Ketiga penelitian Rika Istianingrum dengan judul Degradasi Bahasa Dayak Kenyah. Penelitian ini difokuskan pada faktor terjadinya pergeseran bahasa Kenyah dan usaha yang dilakukan oleh masyarakat Dayak Kenyah dalam mempertahankan bahasanya. Hasil penelitian menunjukkan bahwa faktor-faktor yang mempengarugi pergeseran bahasa Dayak Kenyah adalah: faktor prestise, migrasi dan konsentrasi wilayah, publikasi media massa, dan kekurang mahiran berbahasa Dayak Kenyah. Sedangkan upaya yang dilakukan untuk mempertahankan bahasa Dayak Kenyah adalah melalui lingkungan keluarga, di pasar tradisional, kegiatan keagamaan, kegiatan adat, dan pementasan kesenian.

Perbedaannya dengan penelitian ini adalah pada fokus penelitiannya, yaitu: peneliti yang pertama memfokuskan pada bahasa Ibu di grup WA, peneliti kedua memfokuskan pada Strategi Komunikasi pada Komunikasi Tutorial (Pembelajaran BIPA Kelas Pemula), dan peneliti yang ketiga memfokuskan pada faktor terjadinya pergeseran bahasa Kenyah dan usaha yang dilakukan oleh masyarakat Dayak Kenyah dalam mempertahankan bahasanya. Sedangkan penetiti memfokuskan pada pemertahanan bahasa Sindang pada ranah remaja dan dewasa pada masyarakat Kelurahan Watervang Kecamatan Lubuklinggau Timur 1 Kota Lubuklinggau.

\section{METODE PENELITIAN}

Penelitian ini bertujuan untuk mendeskripsikan sikap pemertahanan bahasa Sindang pada masyarakat di lingkungan remaja dan dewasa menggunakan metode deskriptif kuantitatif untuk mendapatkan pemaparan yang bersifat aktual dan alami mengenai sikap pemertahanan bahasa Sindang pada masyarakat Kelurahan Watervang Kecamatan Lubuklinggau Timur 1 Kota Lubuklinggau. 
Dalam penelitian ini subjek yang diteliti adalah masyarakat Kelurahan Watervang Kecamatan Lubuklinggau Timur 1 Kota Lubuklinggau dari golongan remaja dan dewasa dari populasi yang berjumlah 3833 orang terdiri atas 2.246 orang laki-laki dan 1.587 orang perempuan (Sekretaris Kelurahan Watervang, per Desember 2017). Penetapan subjek penelitian dengan teknik Purpose Sampling adalah teknik pengambilan sampel dengan pertimbangan tertentu sebagaimana dikemukakan Sugiyono (2013). Melalui teknik Purpose Sampling ini subjek penelitian ditetapkan sebanyak 26 orang dari golongan Remaja dan 23 orang dari golongan dewasa. Dengan demikian, total subjek yang diteliti sebanyak 59 orang.

Pengumpulan data dilakukan dengan menggunakan angket (kuesioner) tertutup dengan 20 item pertanyaan dengan alternatif jawaban (option) yang tinggal dipilih oleh responden dalam bentuk tabel. Responden tinggal memberikan tanda centang $(\sqrt{ })$ pada kolom atau tempat yang sesuai dengan karakteristik mereka. Skala yang digunakan dalam angket ini adalah skala likert, dengan lima alternatif jawaban, yaitu sangat setuju (SS), setuju (S), netral (N), tidsk setuju (TS), sangat tidak setuju (STS) yang disebarkan kepada responden berupa dafftar pernyataan secara tertulis yang ditujukan kepada masyarakat pada ranah remaja dan dewasa Kelurahan Watervang Kecamatan Lubuklinggau Timur 1 Kota Lubuklinggau. Uji keabsahan angket dilakukan melalui uji transferabilitas. Dalam uji transferbilitas ini peneliti memberikan lembaran pertanyaan yang didisi oleh responden.

Penyusunan instrumen kuesioner berupa pernyataan positif dan negatif berpatokan pada indikator sikap pemertahanan Bahasa Sindang (bahasa Sindang) mencakup aspek kognisi, afeksi, dan konasi. Aspek konasi mencakup indikator pemerolehan bahasa Sindang tidak alamiah, bahasa Sindang mudah, bahasa Sindang tidak lebih rendah. Untuk aspek afeksi mencakup bangga menggunakan bahasa Sindang, setia menggunakan Bahasa Sindang, dan tanggung jawab menggunakan bahasa Sindang.Sedangkan untuk aspek konasi mencakup siap tanggap.

Analisis data yang digunakan dalam penelitian ini menggunakan teknik penskoran dengan cara menghitung skor total dari jawaban angket yang diberikan oleh responden kemudian dideskripsikan dengan menggunakan skala likert dalam bentuk checklist, untuk setiap jawaban diberi skor yang berbeda. Untuk mengetahui jumblah jawaban dari para responden melalui persentase, yaitu digunakan rumus sebagai berikut: 


$$
\mathrm{P}=\frac{F}{N} \times 100 \%
$$

Keterangan :

$\mathrm{F}=$ Frekuensi yang sedang dicari presentasinya

$\mathrm{N}=$ Number Of Case (Jumlah frekuensi/ banyaknya individu)

$\mathrm{P}=$ Angka persentase (Sudijono, 2004)

Untuk mengetahui gambaran sikap pemertahanan bahasa Sindang pada masyarakat Kelurahan Watervang Kecamatan Lubuklinggau Timur 1 Kota Lubuklinggau maka dilakukan pengelompokan data yang diperoleh ke dalam lima kategori, yaitu sangat baik, baik, cukup baik, kurang baik,

\section{HASIL PENELITIAN}

Penelitian tentang sikap pemertahanan bahasa Sindang pada masyarakat Kelurahan Watervang Kecamatan Lubuklionggau Timur 1 Kota Lubuklinggau dengan jumlah responden sebanyak 59 orang dari ranah remaja dan dewasa menunjukkan adanya perbedaan sikap pemertahanan bahasa Sindang. Berdasarkan hasil analisis data mengenai sikap pemertahanan bahasa Sindang pada masyarakat Kelurahan Watervang Kecamatan Lubuklinggau Timur

Pemertahanan bahasa Sindang pada masyarakat Kelurahan Watervang Kecamatan Lubuklinggau Timur 1 dari golongan remaja pada aspek kognisi dengan rata-rata $(74,45)$, aspek afeksi dengan rata-rata $(70,34)$, dan aspek konasi dengan ratarata $(74,24)$, dari seluruh aspek untuk golongan remaja diperoleh rata-rata $(73,01)$. Selanjutnya dari golongan dewasa dari aspek kognisi dengan rata-rata $(80,06)$, aspek afeksi dengan rata-rata $(81,30)$, dan aspek konasi dengan rata-rata $(80,35)$. Untuk jumlah keseluruhan aspek kognisi, afeksi, dan konasi golongan dewasa yaitu mencapai rata-rata $(80,57)$. Dari hasil perhitungan angket di atas dapat disimpulkan bahwa sikap pemertahanan bahasa Sindang pada masyarakat Kelurahan Watervang Kecamatan Lubuklinggau Timur 1 Kota Lubuklinggau untuk golongan remaja, dan dewasa dari aspek kognisi, afeksi, dan konasi dalam kategori baik dengan rata-rata $(76,79)$. 


\section{PEMBAHASAN}

Masyarakat Lubuklinggau merupakan masyarakat yang heterogen. Penduduknya merupakan penduduk asli dan penduduk pendatang yang berasal dari pulau Jawa dan pulau yang lainnya yang berasal dari daerah dengan suku dan bahasa yang berbeda seperti Jawa, Sunda, Padang, Lampung dan sebagainya.. Oleh karena itu Lubuklinggau dikatakan juga sebagai kota transit karena Lubuklinggau merupakan daerah lintas tengah yang banyak dilalui orang yang akan menuju daerah lain seperti Bengkulu, Padang, Jambi, Medan, bahkan sampai ke Aceh.

Keadaan seperti ini yang menjadikan masyarakat Lubuklinggau sebagai masyarakat yang multingual. Masyarakat seperti ini cenderung mengambil sikap dalam menggunakan bahasa daerahnya B1) dalam berkomunikasi. Sikap masyarakat sebagai upaya untuk menggunakan bahasa daerahnya inilah yang disebut dengan pemertahanan bahasa. Hal inilah yang menyebabkan terjadiya pergeseran bahasa karena pergeseran bahasa terjadi karena perpindahan penduduk, ekonomi, sekolah, dan lain-lain.

Berdasarkan hasil penelitian mengenai pemertahanan bahasa Sindang diketahui bahwa pemertahanan bahasa Sindang yang terjadi pada masyarakat Kelurahan Watervang Kecamatan Lubuklinggau Timur 1 Kota Lubuklinggau dari golongan remaja pada aspek kognisi dengan rata-rata $(74,45)$. Aspek konasi mencakup indikator bahasa Sindang tidak alamiah, bahasa Sindang mudah, bahasa Sindang tidak lebih rendah. Aspek afeksi dengan rata-rata (70,34). Untuk aspek afeksi mencakup bangga menggunakan bahasa Sindang, setia menggunakan Bahasa Sindang, dan tanggung jawab menggunakan bahasa Sindang, dan aspek konasi dengan rata-rata $(74,24)$ aspek konasi mencakup siap tanggap, dari seluruh aspek untuk golongan remaja diperoleh rata-rata $(73,01)$.

Selanjutnya dari golongan dewasa dari aspek kognisi dengan rata-rata $(80,06)$ Aspek konasi mencakup idikator bahasa Sindang tidak alamiah, bahasa Sindang mudah, bahasa Sindang tidak lebih rendah, aspek afeksi dengan rata-rata $(81,30)$. Untuk aspek afeksi mencakup bangga menggunakan bahasa Sindang, setia menggunakan Bahasa Sindang, dan tanggung jawab menggunakan bahasa Sindang, dan aspek konasi dengan rata-rata $(80,35)$, aspek konasi mencakup siap tanggap Untuk jumlah keseluruhan aspek kognisi, afeksi, dan konasi golongan dewasa yaitu mencapai rata- 
rata $(80,57)$. Dari hasil perhitungan angket di atas dapat disimpulkan bahwa sikap pemertahanan bahasa Sindang pada masyarakat Kelurahan Watervang Kecamatan Lubuklinggau Timur 1 Kota Lubuklinggau untuk golongan remaja, dan dewasa dari aspek kognisi, afeksi, dan konasi dalam kategori baik dengan rata-rata $(76,79)$.

Jika dikaitkan dengan teori yang dikemukakan Wijana (2011) bahwa pemertahanan bahasa suatu masyarakat dipengaruhi oleh faktor kebanggaan berbahasa (linguistic pride); kesadaran akan norma (Iawareness loyality) dan loyalitas bahasa (language loyality), dan konsep pemertahanan bahasa yang mencakup perubahan bahasa (language change), peralihan bahasa (language shift), dan kematian bahasa (language death), maka hal ini relevan dengan pendapat Fauzi (Suandi, 2014) dan Fauzi (Nugroho, 2017) bahwa jika suatu komunitas bahasa tidak mampu mempertahankan bahasanya, secara bertahap memungut kosakata bahasa yang lain, maka akan mengarah pada pergeseran bahasa (language shift). dan jika situasi di mana suatu komunitas bahasa berusaha menggunakan bahasanya untuk menjaga bahasa yang dimilikinya baik bahasa daerah atau bahasa ibunya maka sikap masyarakat Kelurahan Watervang Kecamatan Lubuklinggau Timur 1 Kota Lubuklinggau mengarah pada pemertahanan bahasa karena masih mencapai 76,79 (berada dalam kategori baik)

Berdasarkan perolehan kategori sikap pemertahanan bahasa Sindang pada masyarakat Kelurahan Watervang Kecamatan Lubuklinggau Timur 1 Kota Lubuklinggau maka masyarakat masih dapat dikatakan mempertahankan bahasa Sindang meskipun sebagian sudah mengalami peralihan bahasa dan pergeseran bahasa mengingat bahwa bahasa Sindang hidup berdampingan dengan bahasa daerah lain. Faktor penyebab pemerttahanan bahasa Sindang pada golongan remaja pada golongan remaja dan dewasa adalah bilingualisme. Golongan remaja lebih lemah ketimbang golongan tua. Golongan remaja banyak dipengaruhi adanya loyalitas bahasa, dampak perkawinan campuran, latar belakang pendidikan, mobilitas sosial dan faktor-faktor lainnya sehingga wajarlah bila golongan dewasa lebih kuat sikap pemertahanan terhadap bahasa Sindang daripada golongan muda.

\section{SIMPULAN.}

Berdasarkan hasil penelitian dan pembahasan dapat ditarik kesimpulan bahwa sikap pemertahanan bahasa Sindang pada masyarakat Kelurahan Watervang Kecamatan 
Lubuklinggau Timur 1 Kota Lubuklinggau dalam kategori baik pada golongan remaja dan dewasa dengan rata-rata sikap sebesar 76,79. Sikap pemertahanan bahasa Sindang pada kelompok dewasa lebih kuat ketimbang kelompok remaja. Hal ini menunjukkan bahwa kelompok dewasa lebih kuat dalam mempertahankan bahasa Sindang sebagai bahasa asli penduduk Lubuklinggau.

\section{DAFTAR PUSTAKA}

Aslinda dan Syafyahya, L. (2007). Pengantar Sosiolinguistik. Bandung: PT Revika Aditama.

Chaer, A. (2010). Sosiolinguistik Perkenalan Awal. Jakarta: PT Rineka Cipta.

Fatimah. (1996). Fonologi dan Morfologi Bahasa Sindang. Jakarta: Pusbinbangsa.

Maemunah, Emma. (2017). Pemakaian Bahasa Jawa Keluarga Muda di EksKaresidenan Semarang. Balai Bahasa Provinsi Jawa Tengah. Diakses dari Jurnal Jalabahasa. 13(1)

Masinambouw dan Paul Haenen. (2001). Sosiolinguistik. Jakarta: Erlangga.

Muslihah, Nur Nisai. (2016). Society's Attitudes toward Indonesia and Perspective in Facing the ASEAN Economic Community. Paper dipresentasikan di ICEL ${ }^{4 T \text { th }}$ The Fourth International Conference on Education and Language. Bandar Lampung, University Indonesia.

Nugroho, Hasan. (2017). Pemertahanan Bahasa sebagai Strategi Komunikasi pada Kegiatan Tutorial (Pembelajaran BIPA Kelas Pemula). Diakses 20 Desember 2018 dari Jurnal Wacana. 1(1)

Handoyo, Eko A. T. (2015). Studi Masyarakat Indonesia. Yogyakarta: Ombak.

Rianto, Sugeng dan Wagiati. (2016). Pemertahanan Bahasa Sunda oleh Mahasiswa yang Berbahasa Pertama Sunda. Diakses 26 Desember 2018, 2 dari Jurnal Metalingua. 14(2).

Istianingrum, Rika. (2015). Degradasi Bahasa Dayak Kenyah. Diakses 20 Desember 2018 dari Jurnal Stilistika. 8(2).

Sahril. (2016). Pemertahanan Bahasa Ibu di Grup WA. Diakses dari Jurnal Ranah 5(1): 43-52.

Suandi, I. N. (2014). Sosiolinguistik. Yogyakarta: Graha Ilmu.

Sudijono, A. (2004). Pengantar Statistik Pendidikan . Jakarta: PT Raja Grafindo 


\section{Persada.}

Sugiyono. (2013). Metode Penelitian Pendidikan Pendekatan Kuantitatif, Kualitatif dan $R \& D$. Bandung: Alfabeta.

Wijana, D. d. (2011). Sosiolinguistik Kajian Teori dan Analisis. Yogyakarta: Pustaka Pelajar. 